\title{
A Sociological Analysis of Road Accidents among Teenagers Motor Bike Riders in District Dir Lower, Khyber Pakhtunkhwa
}

\author{
5. Ullah (Sana Ullah)', A. Naz (Arab Naz)², B. Ali (Basit Ali)
}

${ }^{1}$ PhD Scholar (Sociology) University of Malakand, Khyber Pakhtunkhwa,

Original Article Pakistan

${ }^{2}$ Professor in Sociology, Dean Social Sciences, University of Malakand, KPK, Pakistan

${ }^{3}$ PhD Scholar, Department of Sociology, AWKUM, Khyber Pakhtunkhwa, Pakistan

\section{E-mail address:}

sana_871@yahoo.com

\section{Reprint address:}

Sana Ullah

University of Malakand

Khyber Pakhtunkhwa

Pakistan

Source: Clinical Social Work and Health Intervention

Volume: 10

Issue: 1

Pages: $64-74$

Cited references: 24

\section{Reviewers:}

Tadeusz Bak

Warsaw Management University, Poland

Daniel J. West, Jr.

University of Scranton, Department of Health Administration and Human Resources, USA

\section{Key words:}

Road Accidents. Teenagers. Sociological Analysis. Death \& Injuries. Health Threat.

\section{Publisher:}

International Society of Applied Preventive Medicine i-gap

CSWHI 2019; 10(1): 64 - 74; DOI 10.22359/cswhi_10_1_10 @ 2019 Clinical Social Work and Health Intervention

\section{Abstract:}

Road accidents in general and among motor bike riders in particular are one of the growing health issues these days in Pakistan. Road accidents are a global concern, but the situation has become worsened particularly in Pakistan. It is an unfortunate fact that the issue is not given as 
much importance as the issue persists. In road crash accidents, Pakistan stands $1^{\text {st }}$ in Asia and $48^{\text {th }}$ in the world, while the metropolitan city of Pakistan, Karachi is ranked as fourth in the list. Continuous fatal crashes among teenagers motor bike riders results in numerable deaths and injuries in Pakistan. Regular movement of military freight, rapid urbanization, excessive motorization, and congestion, increased the risks to road traffic users. The current study was carried out in District Dir Lower, province of Khyber Pakhtunkhwa, Pakistan. Primary data was collected from 30 respondents conveniently selected, including casualty staff of DHQ Timergara, THQ Chakdara, THQ Shamshi Khan Talash, parents, teenage motor bike riders, and traffic police inspectors. The collected data was qualitatively and thematically analyzed in order to clarify the issue under study. The study concluded that multiple social, economic and cultural factors contribute to road accidents among teenagers motor bike riders. The study also forwarded some suggestions.

\section{Introduction}

The use of motorcycles has increasingly become a popular means of transport in low and middle income countries around the world (World Health Organization, 2006). Every day, thousands of people lose their lives in roads accidents, while millions other are left with disabilities or emotional scars that they will carry for the rest of their lives (MacLeod et al., 2010). Around the world, children, teenagers and young adults are among the most vulnerable. Every hour of the day, forty youngsters die as a result of road traffic crashes, which means that every day another one thousand families have to cope with the unexpected loss of a loved one (Toroyan, 2015). The death of a teenager from preventable incidents further adds to the pain and suffering, and leave their families with emotional wounds that take decades to heal. The future of any country is its young people, and a nation cannot afford losing their youth on road traffic crashes. Males are more involved in road accidents, and similar results are found in various research studies, that young age males are more likely to be the victim in road traffic crashes (Waylen \& McKenna, 2008). Similarly, among drivers, young males under the age of 25 years are almost three times as likely to be killed as their female counterparts. This may reflect the fact that because of the prevalent socio-cultural reasons males are more likely to be on the roads, and have a greater propensity to take risks as compared to females (Flamme, 1998). Besides, the socio-economic condition of a family also affects the likelihood of a teenage or youth being killed or injured in a road traffic crash, while those from economically poor backgrounds are at the greatest risk. This relationship is found not only between higher-income and lower-income countries, but within countries as well (Nantulya \& Reich, 2002).

Road accidents among teenage motorbike riders are a global concern causing thousands of deaths and injuries each day, and traffic fatalities have increased by $46 \%$ from 1990 to 2010, and are expected to jump from the eighth to the fifth leading cause of death by 2030 (WHO, 2008). Motorbike accidents in general and among teenagers are particularly increasing and an estimated $92 \%$ of the annual road-traffic fatalities throughout the world occur in developing countries like Pakistan (WHO, 
2013). While looking to this as a global concern, the United Nations has also declared the current decade 2011-2020 as the decade of Action for Road Safety (UNO, 2010). So, there is only one year left. Motorcycle riding among teenagers is rapidly increasing in Pakistan, attracting a much wider number of young adults than in the past decades. The overall number of road related accidents and deaths in Pakistan have been greatly increased in recent years. Many socio-cultural factors such as lack of driving experience, inappropriate safety awareness, training and education among teenage motorbike riders has increased the risks of road crashes among teenager riders (Savolainen \& Mannering, 2008 and Lin \& Kraus, 2009). Unfortunately, in District Dir Lower motorbike-related collisions among teenagers has been on the rise in recent years, and the amount of motorbike-related crashes in Dir Lower is much higher compared to crashes of other vehicles. The increased accident rates are due to a number of factors, including the amount of driving experience, family control, peer factors, lack of awareness regarding traffic rules, license status, and education level of the drivers. The issue calls for immediate attention of the research scholar to explore its socio-cultural causes to minimize the intensity of the issue in global as well as local context.

\section{Study Rationale}

Road accidents among teenage motorbike riders is a global concern and has emerged as a serious health issue. It costs millions of lives and left many million people either disabled or injured every year across the globe (Toroyan, 2015). The current figure of road related deaths shows that by 2020 it would be the world's third leading cause of deaths, while the introduction of two and three-wheeled vehicles has further worsened the situation (Astrom, Moshiro, Hemed, \& Heuch, 2006 \& Peden, 2004). It is predicated from the present rapid increase in motorbikes that by 2035 the two and three wheelers will increase by $175 \%$ reaching 550 million (The Clean Air Initiative for Asian Cities, 2011). The rapid rise is increasingly linked to the socio-economic situation of a country, as more citizens mainly purchase two and three wheeled vehicles, which results in the rise of road-traffic injuries and deaths (Kopits \& Cropper, 2005; Paulozzi, Ryan, Espita \& Hardeman, 2007). In this influx motorcycles are of particular concern because motorcycles are more dangerous than any other type of motorized vehicle, and motorcyclists were about 30 times more likely to die in a traffic crash than a passenger in a car (National Highway Traffic Safety Administration, 2012).

Approximately, 1,000 young people under the age of 25 years are killed in road traffic crashes on daily basis, while another 1.2 million people die of road crashes each year particularly in low-income and middle-income countries (WHO, 2013). Similarly, road traffic injuries are the leading cause of death among 15-19-year-olds teenagers; the second leading cause of death for those in the 10-14-years; 20-24-years age (Beeck, Borsboom, \& Mackenbach, 2000). Further, the vast majority i.e. $90 \%$ of all road traffic deaths and injuries occur in low-income and middle-income countries including Pakistan (Peden et al., 2004); while children and young people under the age of 25 years account for over $30 \%$ of those who are killed or injured in road traffic crashes (WHO, 2002). Besides, many children and young people who have been involved in road traffic collisions are left with long-term or permanent injuries or disabilities (Jacob, Aeron \& Astrop, 2000). Road accidents among teenage motorbike riders is a social issue having multiple socio-economic and cultural factors. But, the issue is always dealt with in relation to engineering perspectives 
looking into road designs. However, the present study was conducted in District Dir Lower, Khyber Pakhtunkhwa, Pakistan in order to analyze the socio-cultural factors behind the issue which is of great sociological significance but very little has been done so far in exploring the social causes/factors of the issue, on which the present research will specifically focus.

\section{Methodology}

The study was conducted in District Dir Lower. Primary data was collected from a total of 30 respondents using convenient sampling techniques. In this regard, out of the total sample 10 respondents were teenage motorbike riders who have been in motorbike road accidents but were survived after sustaining minor or severe injuries. Further, 6 casualty staff members were selected, 2 each from District Headquarter Hospital Timergara, Tehsil Headquarter Hospital Chakdara and Tehsil Headquarter Hospital Shamshi Khan Talash Dir Lower. Furthermore, data was also collected from 8 parents whose son either died or sustained injuries because of motorbike accidents. Similarly, data was also collected from 6 Traffic Police Inspectors two each in Timergara, Talash and Chakdara in order to know their opinions regarding the issue. The study was qualitative in nature and data was collected through interview using an interview guide. The respondents were divided into three categories and codes were developed for each category of respondents such as for teenage motorbike riders' code was (1TMR) and for casualty staff members' code was (2CSM) for the parents of the teenagers, the code was (3PTMR) and for Traffic Police Inspectors the code was (4TPI). Also separate points, topics or questions were prepared and asked from all categories of the respondents. In the current study, a sample of 30 respondents is justified, because in similar qualitative nature studies conducted by Delawala \& Ahmad in 1995 also utilized 18 and 30 sample size respectively.

\section{Results and Discussion}

\section{Part-A}

\section{Demographic Characteristics of the Teenage Motorbike Riders}

\begin{tabular}{|l|c|c|c|}
\hline Age Group & Frequency & Percentage & Total \\
\hline $13-14$ & 2 & 20 & 2 \\
\hline $14-15$ & 3 & 30 & 3 \\
\hline $15-17$ & 3 & 30 & 3 \\
\hline $16-18$ & 2 & 20 & 2 \\
\hline Total & $\mathbf{1 0}$ & $\mathbf{1 0 0}$ & $\mathbf{1 0}$ \\
\hline $\begin{array}{l}\text { Family } \\
\text { Types }\end{array}$ & Frequency & Percentage & Total \\
\hline $\begin{array}{l}\text { Joint } \\
\text { Family }\end{array}$ & 4 & 40 & 4 \\
\hline $\begin{array}{l}\text { Nuclear } \\
\text { Family }\end{array}$ & 4 & 40 & 4 \\
\hline $\begin{array}{l}\text { Extended } \\
\text { Family }\end{array}$ & 2 & 20 & 2 \\
\hline Total & $\mathbf{1 0}$ & $\mathbf{1 0 0}$ & $\mathbf{1 0}$ \\
\hline Education & Frequency & Percentage & Total \\
\hline Illiterate & 3 & 30 & 3 \\
\hline Primary & 2 & 30 & 2 \\
\hline Middle & 3 & 30 & 3 \\
\hline $\begin{array}{l}\text { Matric \& } \\
\text { above }\end{array}$ & 2 & 20 & 2 \\
\hline Total & $\mathbf{1 0}$ & $\mathbf{1 0 0}$ & $\mathbf{1 0}$ \\
\hline $\begin{array}{l}\text { Marital } \\
\text { Status }\end{array}$ & 2 & 20 & 2 \\
\hline Married & $\mathbf{1 0}$ & $\mathbf{1 0 0}$ & $\mathbf{1 0}$ \\
\hline Unmarried & 80 & \\
\hline Total & & & \\
\hline
\end{tabular}

The above table is about the demographic characteristics of the first category of respondents. Out of the total 10 respondents $2(20 \%)$ were between the age of $13-14 ; 3$ (30\%) between 14-15; $3(30 \%)$ between 15 17; the remaining $2(20 \%)$ between 16-18 years. Further, $4(40 \%)$ respondents each 
were living in joint and nuclear families; $2(20 \%)$ were living in extended families. Further, out of the total respondents $3(30 \%)$ were illiterate, $2(20 \%)$ were having primary education: $3(30 \%)$ were educated up to middle level while the remaining $2(20 \%)$ were educated up to matric and above. Out of the total respondents a very small number i.e. $2(20 \%)$ were married; the remaining 8 $(80 \%)$ were unmarried.

\section{Demographic Characteristics of the Casualty Staff Members}

\begin{tabular}{|l|c|c|c|}
\hline Designation & Frequency & Percentage & Total \\
\hline $\begin{array}{l}\text { Senior } \\
\text { Medical } \\
\text { officer }\end{array}$ & 2 & 33.3 & 2 \\
\hline $\begin{array}{l}\text { Medical } \\
\text { officer }\end{array}$ & 2 & 33.3 & 2 \\
\hline Dispenser & 1 & 16.6 & 1 \\
\hline Nurse & 1 & 16.6 & 1 \\
\hline Total & 6 & $\mathbf{1 0 0}$ & 6 \\
\hline Duty Hours & Frequency & Percentage & Total \\
\hline $\begin{array}{l}800 \text { am - } \\
200 \text { Pm }\end{array}$ & 3 & 50 & 3 \\
\hline $\begin{array}{l}200 \text { pm - } \\
800 \text { Pm }\end{array}$ & 2 & 33.3 & 2 \\
\hline $\begin{array}{l}800 \text { pm - } \\
800 \text { am }\end{array}$ & 1 & 16.6 & 1 \\
\hline Total & $\mathbf{6}$ & $\mathbf{1 0 0}$ & $\mathbf{6}$ \\
\hline $\begin{array}{l}\text { Cases/Acci- } \\
\text { dents relat- } \\
\text { ed emer- } \\
\text { gency/s } \\
\text { Attended } \\
\text { during } \\
\text { duty per } \\
\text { week }\end{array}$ & Frequency & Percentage & Total \\
\hline 1-2 & 2 & 33.3 & 2 \\
\hline 2-3 & 50 & 3 \\
\hline 3-4 & 16.6 & 1 \\
\hline Total & & 100 & 6 \\
\hline
\end{tabular}

The above table portrays information about the second category of respondents i.e. casualty staff members. In this regard, out of the total $2(33.3 \%)$ respondents were senior medical officers; 3 (33.3\%) were medical officers; $1(16.6 \%)$ were the category of dispensers; 1 (16.6\%) were nurses. The table further indicates the duty hours of respondents and out of the total $3(50 \%)$ respondents' duty hours were from 8:00 am to 2: $00 \mathrm{pm} ; 2(33.3 \%)$ from $2: 00 \mathrm{pm}$ to $8: 00$ pm; only $1(16.6 \%)$ from $8: 00 \mathrm{pm}$ to $8: 00$ am. Also, the table shows that the number of motorbike accident cases attended by respondents in their duty hours; 2 (33.3\%) attended from 1-2, motorbike accidents cases; $3(50 \%)$ attended 2-3 motorbike accidents in duty hours; 1 (16.6\%) attended 3-4 motorbike accident cases during their duty hours.

\section{Demographic Information of the Parents of Teenage Motorbike Riders}

\begin{tabular}{|l|c|c|c|}
\hline $\begin{array}{c}\text { Age } \\
\text { Group }\end{array}$ & Frequency & Percentage & Total \\
\hline $35-40$ & 3 & 37.5 & 3 \\
\hline $41-45$ & 2 & 25 & 2 \\
\hline $45-50$ & 2 & 25 & 2 \\
\hline $51-55$ & 1 & 12.5 & 1 \\
\hline Total & $\mathbf{8}$ & $\mathbf{1 0 0}$ & $\mathbf{8}$ \\
\hline $\begin{array}{l}\text { Family } \\
\text { Types }\end{array}$ & Frequency & Percentage & Total \\
\hline Joint Family & 3 & 37.5 & 3 \\
\hline $\begin{array}{l}\text { Nuclear } \\
\text { Family }\end{array}$ & 3 & 37.5 & 3 \\
\hline $\begin{array}{l}\text { Extended } \\
\text { Family }\end{array}$ & 2 & 25 & 2 \\
\hline Total & $\mathbf{8}$ & $\mathbf{1 0 0}$ & $\mathbf{8}$ \\
\hline Education & Frequency & Percentage & Total \\
\hline Illiterate & 3 & 37.5 & 3 \\
\hline Primary & 2 & 25 & 2 \\
\hline Middle & 2 & 25 & 2 \\
\hline $\begin{array}{l}\text { Matric \& } \\
\text { above }\end{array}$ & 1 & 12.5 & 1 \\
\hline Total & $\mathbf{8}$ & $\mathbf{1 0 0}$ & $\mathbf{8}$ \\
\hline
\end{tabular}


The table above is about the demographic characteristics of third category (the parents of teenage motorbike riders). The analysis shows that out of the total respondents $3(37.5 \%)$ were between the age of $35-40 ; 2$ (25\%) between 41-45; 2 (25\%) between 45$50 ; 1(12.5 \%)$ between $51-55$ years. Similarly, the table indicate that out of the total respondents $03(37.5 \%)$ were belonging to joint family system, 03(37.5\%) were living in nuclear families, and rest of respondents i.e. $02(25 \%)$ were living in extended family system. Further, the education status of the respondents shows that majority of them i.e. $03(37.5 \%)$ were illiterate, 02 (25\%) each were educated up to primary and middle level, while only a small number i.e. $01(12.5 \%)$ education level was matric and above.

\section{Part-2}

\section{Thematic Discussion}

\section{Teenager Developmental Factors and their Motorbike Accidents}

Teenagers do not understand reaction to complex traffic situations in the same way as adults and because of their developmental immaturity they lack certain abilities that adults possess in handling difficult traffic environments. Their immaturity increases their risk to road traffic crashes. In addition, in their teens they want to exert physical energy; explore many things; want to play complicated and risky games which expose them to greater risks of being hit by another vehicle. Besides, teenagers may unconsciously take risks because they lack appropriate skills; seek sensation; seek new experiences irrespective of the risks associated to the experiences. This sensation seeking has been on the rise between the ages of 9 to 14 years, peaking in late adolescence or the early 20 s, and then declining steadily with age (Arnett, 2002 \& Zuckerman, 1994). Similar views were also by respondents during field interviews:

"...... It is true that children in their teenage are unable to handle difficult situation like adult. They are physically as well as mentally immature, seeking fun in everything including driving on the road ...." (2CSM \& 3PTMR)

Another respondent said that:

"...... Children in their teenage are immature and they are playing on the road with their motorbikes, which expose them to road crashes....." (2CSM).

Risk taking is a normal occurrence during adolescence, a distinguished period of an individual's development (Courtois, 2011). Barbalat et al. (2010) imply that adolescents tend to choose riskiest options because they like risk taking more than adults and ignore the future consequences of their choices. Regarding risk seeking among teenager motorbike riders and their road crashes a respondent was of the opinion that:

"..... Teenagers are unaware of the consequences of risk taking on the roads because of their immaturity. They are absorbed in their own without having any consideration for the surroundings....." (2CSM \& 3PTMR).

Most of the risky behaviors are taken at adolescence which is both very harmful for a teenager himself as well as for others. These behaviors are commonly found in those individuals who are self-absorbed with egotistic impulse, having invalid experience and passing through an identity crisis, particularly increase his sensations seeking in speed and taking risks on the road (Coslin, 2003).

\section{Parental Guidance, Support \& Road Accidents}

Parents play an important role in formation of the behavior of their young children, 
and also make important decisions regarding the exposure of their children to risks. They also influence how often or how long children may be in traffic or on the road, and whether or not their children use child restraints or helmets. Similarly, parents serve as important role models for their children who in turn learn and imitate adults' actions and risks (OECD, 2004). There are also various learned behavioral factors among adults in relation to road traffic accidents including motorbike accidents. It was argued by a respondent during field interview that:

"..... I will feel no hesitation in saying that we the parents are responsible for the situation. Being a father I have to socialize my children in a decent way. Also providing motorbike to our teenage children is our fault...." (2CSM \& 3PTMR).

In this regard, a study conducted by Bingham and Shope (2004) about risky driving among adolescents and young adults found that certain risky driving behavior among young drivers were the result of low level of parental monitoring, an increased parental permissiveness, and a weaker social bond. In fact, these individuals are likely to endanger themselves and others through risky driving (Bingham \& Shope, 2004). In this regard, a respondent shared that:

".......Parents has no check on their children, and do not monitor their activities. While purchase of a motorbike for a teenage child is a great mistake on the part of most parents....."(3PTMR).

Family environment and children socialization influence adolescent driving behavior and in a study by Taubman and Katz, (1997) found a close relation between risky driving, road accidents and family environment. Those parents of the young motorbike riders who see their parents as good role models, who are commitment to road safety and follow the define speed limits on the roads, tended to take lesser risks and they drove more carefully and less aggressively. However, teenagers whose parents are not following road safety measure and speed limits are taking more risks while driving (Jonah, Thiessen and Yeung, 2001). For validation an extract from an interview is mention below:

".....I will say that those parents do don't follow traffic rules and speed limits while driving set bad example for their, and they imitate our irresponsible road safety behavior..." (2CSM \& 3PTMR).

Another respondent said that:

"...... In solving the issue the role of parents is very important. They should have some control over their children in order to bring reduction in the intensity of the issue ....." (4TPI).

Similarly, family factor is the most important in the creation of a high-risk profile in young drivers, and consequently highrisk drivers maintained the risky driving behavior of their parents, whereas low-risk drivers had attitudes to road safety similar their parents (Sabate, Arnau \& Sala, 2014). Improvements in parental supervisory role at driving learning stage also promote teen drivers skills acquisition and reduction of their risky driving behaviors (Curry, Peek, Haman \& Mirman, 2015). Conclusively, parents' socialization and family environment play significant role in behavior formation of the individual in general as well as related to driving.

\section{Motorbike Accidents and Personality Dimensions}

Two factors seems to be greatly associated with road accidents i.e. factors related to traffic environment and the human determinant i.e. the driver himself (Chliaoutakis, Demakakos, Tzamalouka, 2002) while the majority of the accidents are associated with human factor. Social factors are greatly contributing to road accidents, and accident of young motorbike drivers was associated with lack of tolerance, getting 
easily irritated, expressing aggression and developing hostility towards other drivers, and not being able to control his/her emotions (Chliaoutakis et al., 2012). Similarly, it was found in a study conducted by Norris, Matthews \& Riad (2000), that road accidents among motorbike riders is strongly influenced by high hostility among drivers on road and their poor self-esteem. Field information in this context reflects similar findings and a respondent explained that:

“...... Teenage motorbike drivers are indeed emotional, and lack tolerance. In order bypass one another they get involved in excessive speed......" (2CSM \& 3PTMR).

In this context similar studies indicate that personality factors such as mental health, depression, aggression contribute to road accidents among young motorbike riders aged between 18 and 24 years (Javadi, Azad, Tahmasebi, Rafiei \& Tajlili, 2015) and put the motorbike riders in high risk driving and life threatening consequences. Another respondent added that:

“.... In my opinion risky driving, over speeding and driving without caring for traffic rules are the major causes of road accidents among teenagers' motorbike riders....."(4TPI).

Another respondent admitted that:

“.... I have to admit that the risky attitude, over speeding and aggression during driving is putting our children at risk...." (2CSM).

There also exist strongest correlations between risky driving patterns and antisocial behavior, excessive alcohol consumption, social status, civic engagement, peer relationships and gender (Vassallo, Lahausse \& Edwards, 2016). However, the risk taking characteristics mostly exist in teenagers and they have poor hazard anticipation skills which put the young motorbike drivers to the risks of road accidents (Waylen, McKenna, 2008 \& McDonald, Goodwin, Pradhan \& William, 2015).

\section{Teenager Motorbike Accidents and its Relation to Speed}

High speed increases the chance of death or severe injury among all road users particularly among youth. In addition, in higher speed it becomes difficult for a driver to stop and avoid an accident. Over speeding is much more likely to be a factor in a fatal crash when the driver is under 25 years old (Paris, Transport Research Centre, 2006), and it is amongst the most common traffic violation committed by young drivers in the initial years of driving (Australian Transport Safety Bureau, 2002). Among the young two-wheeler riders' speeding inclination is linked to other factors including general attitude to riding, riding behaviors i.e., engaging in competition and stunts, motives associated with riding fast, sensation seeking and traffic violations (Michael, Sharma, Mehrotra, Banu, Kumar \& Sudhir, 2015). Having inclination towards high speed is one amongst many factors that increase the risks of accident among teenager motorbike riders. In this regard a respondent also shared that:

"......I will argue that most of the motorbike accidents are because of over speeding. In order to bypass others on the roads these young drivers cross speed limits and violate traffic rules and safety measures ..." (4TPI).

Similarly, research studies indicate that in over speeding men have significantly greater inclination than women and the inclination towards over speeding is increasing when these drivers are getting more experience in driving (Styles et al., 2005). While among young motorcyclists (aged 10 - 16 years) the more the rider had experience the higher was the risk of accident (Rathinama, Nairb, Guptaa, Joshia \& Bansala, 2007). During field interviews similar views were shared by respondents, an extract from an interview mentioned: 
“......In my opinion both the experienced and inexperienced drivers are involved in risky speed. But an accident does not care for experience and inexperience but it is a sudden occurrence......" (2CSM \& 4TPI).

Another respondent argued that:

“.... Teenagers are unaware of road safety measures and their over speed on the road is for competition, enjoyment and showing the superiority of himself and his bike...." (4TPI).

Research studies found that $35 \%$ of young motorbike riders did not respect safety distances from other vehicles; $20 \%$ of them were already involved in an accident (Michael, Sharma, Mehrotra, 2014). Over speeding was influenced by many factors such as lack of awareness about road safety; motives for speeding; speed competition; seeking enjoyment; desire to reduce travel time (Michael, Kumar \& Sudhir, 2014). Conclusively, high speed, violating traffic rules, involving in speed competition on roads and seeking enjoyment in high speed were the main factors of road accidents among teenage motorbike riders.

\section{Lack of Protection, Driving Without a License and Over Loading}

Road safety is the biggest problem among teenage motorcyclist which makes them more vulnerable to accident (Ahmad \& Nguyen, 2003). Furthermore, motorcyclists despite having high speeds do not wear helmets or provide helmets. An extract of interview:

“.... In my opinion most of motorcycle riders ignore road safety i.e. not wearing helmet, which is most dangerous...." (4TPI).

Similarly, the majority of the young motorbike riders do not possess a driving license. They are also not aware of the existence of the traffic rules and road signs; violate traffic rules; overestimate their driving skills (Chiu, Kuo, Hung \& Chen, 2000). Similar findings were also found during field interviews and a respondent was of the view that:

"..... Majority of the motorcycle drivers do not have a license, and violate traffic rules regularly...." (4TPI).

In this regard, excessive carriage of passengers and goods also cause road accidents among motorbike riders. In rural as well as in urban areas there are tendencies among young motorcyclists to carry excessive passengers on one motorcycle, including heavy and hazardous goods like heavy petrol. A respondent argued that:

".... Motorcycle is used for carrying more than one person. Also various goods of daily use are also transported through motorcycles....."(2CSM \& 3PTMR, 4TPI).

\section{Conclusion}

The current research focused on the socio-cultural factors of road accidents among teenage motorbike riders in District Dir Lower, of Khyber Pakhtunkhwa. The issue was assessed with a sociological lens in order to highlight the socio-cultural aspects of the issue. The research concluded that road traffic accidents among teenage motorbike riders are increasing and result in many deaths, injuries and material loss around the world, including Pakistan. The young generation is more involved in accidents of motorbike due to several socio-cultural factors including their immaturity; lack of skills and experience; lack of parental control; inappropriate riding skills; desire for high speed; sensation seeking; lack of awareness regarding traffic rules and road safety measures. During the study, ilt was also found that road speed competition and stunt behavior were considered as fun; performed for show off and self-satisfaction; most motorcyclists had an accident performing 
stunts or competitions. The study also found that road accidents among teenage motorbike riders is a social issue and the research has provided a better insight into the social factors influencing rider intentions, behavior and serious crashes.

\section{Recommendations}

Although there is no clear cut outline for avoiding road accidents, the research outlines certain suggestions to reduce road traffic crashes among youth particularly among teenage motorbike riders. In light of the findings of the research there is a dire need to look into the issue socially, focusing on creation of awareness; knowledge regarding traffic rules; recognition of various signals; use of road safety measures. The issue also requires financial investments in prevention efforts, and during designing of road safety initiatives policy-makers and leaders need to recognize young motorbike riders' vulnerabilities as well as their inexperience, developmental needs and allocate separate routes for them. In addition, the traffic department should improve license issuing system, i.e. issue license after skill and written test; ensure the implementation of traffic laws; make 18 years as a minimum age for motorbike riding. There is also need to challenge the notion that road traffic crashes are unavoidable; make room for a pro-active, preventive approaches in order to reduce motorbike accidents among teenagers preventing numerous deaths and injuries on the roads.

\section{References}

1. OECD/ITF (2015) Road Safety Annual Report 2015. Paris: OECD Publishing; (2015).

2. DAYAN J, GUILLERY-GIRARD B (2011) Conduites adolescentes et développement cérébral: psychanalyse et neurosciences. Adolescence 77 (3):479-515.10.3917/ ado.077.0479.
3. COSLIN PG (2003) Les conduites à risque à l'adolescence. Paris: Armand Colin $224 \mathrm{p}$.

4. CHLIAOUTAKIS JE, DEMAKAKOS P, TZAMALOUKAG, BAKOUV, KOUMAKI M, DARVIRI C (2002) Aggressive behavior while driving as predictor of self-reported car crashes. J Safety Res 32:431-43.10.1016/ S0022-4375(02)00053-1.

5. JAVADI SMH, AZAD HF, TAHMASEBI S, RAFIEI H, RAHGOZAR M, TAJLILI A (2015) Study of psycho-social factors affecting traffic accidents among young boys in Tehran. Iran Red Crescent Med J 17(7):1-8.10.5812/ircmj.22080v2.

6. VASSALLO S, LAHAUSSE J, EDWARDS B. (2016) Factors affecting stability and change in risky driving from late adolescence to the late twenties. Accid Anal Prev 88:77-87.10.1016/j.aap.2015.12.010.

7. WAYLEN AE, MCKENNA FP (2008) Risky attitudes towards road use in pre-drivers. Accid Anal Prev 40(3):905-11.10.1016/ j.aap.2007.10.005.

8. MCDONALD CC, GOODWINAH, PRADHAN AK, ROMOSER MR, WILLIAMS AF (2015) A review of hazard anticipation training programs for young drivers. J Adolescent Health 57(1):15-23.10.1016/j. jadohealth.2015.02.013.

9. MICHAEL RJ, SHARMA MK, MEHROTRA S, BANU H, KUMAR R, SUDHIR PM, ET AL. (2014) Inclination to speeding and its correlates among two-wheeler riding Indian youth. Ind Psychiatr J23:10510.10.4103/0972-6748.151676.

10. STYLES T, IMBERGER K, CATCHPOLE J (2005) Understanding Risk-Taking by Young Male Drivers. Research Report ARR 363. Vermont South, VIC: ARRB Group.

11. RATHINAMA C, NAIRB N, GUPTAA A, JOSHIA S, BANSALA S (2007) Self-reported motorcycle riding behavior among school children in India. Accid Anal Prev 39:334-9.10.1016/j.aap.2006.09.002.

12. SAIFUZZAMAN M, HAQUE M, ZHENG Z, WASHINGTON S (2015) Impact of 
mobile phone use on car-following behavior of young drivers. Accident Anal Prevention 82:10-9.10.1016/j.aap.2015.05.001.

13. WHITE MP, EISER JR, HARRIS PR Risk perceptions of mobile phone use while driving. Risk.

14. BINGHAM CR, SHOPE JT (2004) Adolescent developmental antecedents of risky driving among young adults. J Stud Alcohol(2004) 65:84-94.10.15288/jsa.2004.65.84.

15. TAUBMAN-BEN-ARI O, KATZ-BENAMI L (2013) Family climate for road safety: a new concept and measure. Accid Anal Prev (2013) 54:1-14.10.1016/j. aap.2013.02.001.

16. PEDEN M ET AL. (2004) eds. World report on road traffic injury prevention. Geneva, World Health Organization.

17. ASTROM A N, MOSHIRO C, HEMED Y, HEUCH I, KVALE G, (2006) Perceived susceptibility to and perceived causes of road traffic injuries in an urban and rural area of Tanzania. Accident Analysis and Prevention 38 54-62.

18. TOROYAN T (2015) "Global status report on road safety 2015," Supporting a decade of action. Geneva: World Health Organization, Department of Violence and Injury Prevention and Disability, (2015).
19. WORLD HEALTH ORGANIZATION (2013) Global Status Report on Road Safety 2013: Supporting a decade of action. Author; Geneva: 2013.

20. JACOBS G, AERON-THOMAS A, ASTROP A (2000) Estimating global road fatalities. Crowthorne, Transport Research Laboratory, (TRL Report 445).

21. ARNETT J (2002) Developmental sources of crash risk in young drivers. Injury Prevention 8 (Suppl II): ii17-ii23.

22. ZUCKERMAN M (1994) Behavioral expressions and biological bases of sensation seeking. New York, NY, Cambridge University Press.

23. SAVOLAINEN P, MANNERING F (2008) Effectiveness of Motorcycle Training and Motorcyclists' Risk-Taking Behavior published by Transportation Research Board of the National Academies.

24. LA FLAMME L (1998) Social inequality in injury risks: knowledge accumulated and plans for the future. Stockholm, National Institute of Public Health.

25. NANTULYA WM, REICH M (2002) The neglected epidemic: road traffic injuries in developing countries. British Medical Journal 324:1139-1141. 